\title{
Activation of cumulus-free equine oocytes: effect of maturation medium, calcium ionophore concentration and duration of cycloheximide exposure
}

\author{
Y. H. Choi ${ }^{1}$, C. C. Love' ${ }^{1}$, D. D. Varner², J. A. Thompson² \\ and K. Hinrichs ${ }^{1 *}$ \\ ${ }^{1}$ Department of Veterinary Physiology and Pharmacology and ${ }^{2}$ Large Animal Medicine \\ and Surgery, College of Veterinary Medicine, Texas A\&M University, College Station, \\ TX 77843-4466, USA
}

Two different culture media (TCM-199 and follicular fluid), two activation treatments (10 and $50 \mu \mathrm{mol}$ calcium ionophore $\mathrm{I}^{-1}$ ) and three culture periods with cycloheximide were evaluated to find effective culture conditions for activation of cumulus-free equine oocytes. Oocytes were collected by scraping the follicle walls of ovaries obtained from an abattoir. Oocytes with expanded cumuli were matured at $38.2^{\circ} \mathrm{C}$ in a humidified atmosphere of $5 \% \mathrm{CO}_{2}$ in air, in either TCM-199 with $10 \%$ fetal bovine serum (FBS) and $5 \mu \mathrm{U} F S \mathrm{ml}^{-1}$, or in $100 \%$ follicular fluid derived from a preovulatory follicle $24 \mathrm{~h}$ after injection of hCG. After 40-42 h of in vitro maturation, oocytes were denuded by gentle pipetting in TCM-199 plus 10\% FBS with hyaluronidase. Oocytes with intact cytoplasmic membranes $(n=398 ; 94 \%$ presumed metaphase II) were treated in protein-free PBS with 10 or $50 \mu \mathrm{mol}$ calcium ionophore $\mathrm{I}^{-1}$ for $5 \mathrm{~min}$. After washing, the oocytes were cultured in TCM-199 containing
$10 \%$ FBS and $10 \mu \mathrm{g}$ cycloheximide $\mathrm{ml}^{-1}$ for $6 \mathrm{~h}$, in cycloheximide for $6 \mathrm{~h}$ and then in cycloheximide-free medium for $18 \mathrm{~h}$, or in cycloheximide for $24 \mathrm{~h}$. The oocytes were fixed and evaluated by fluorescence microscopy. Oocytes with pronucleus I-II (dense to decondensing chromatin), pronucleus III-IV (decondensed chromatin) or progressing towards the first cleavage division were considered activated. The activation rate for oocytes matured in TCM-199 was significantly $(P<0.05)$ higher than for oocytes matured in follicular fluid $(49 \%(99 / 204)$ versus $35 \%(60 / 171)$, respectively; $P<0.05)$. Culture with cycloheximide for $24 \mathrm{~h}$ resulted in a significantly higher rate of activation $(67 \%, 74 / 111)$ than did the $6 \mathrm{~h}(33 \%$, 44/136) or $6 \mathrm{~h}$ plus $18 \mathrm{~h}(32 \%, 41 / 128)$ treatments. The highest rate of activation $(82 \%)$ was observed in oocytes matured in TCM-199, treated with $50 \mu \mathrm{mol}$ calcium ionophore $\mathrm{I}^{-1}$ and cultured with cycloheximide for $24 \mathrm{~h}$.

\section{Introduction}

Offspring cloned from somatic cells have been reported in several species, including sheep (Wilmut et al., 1997), mice (Wakayama et al., 1998), cattle (Kato et al., 1998), goats (Baguisi et al., 1999) and pigs (Onishi et al., 2000; Polejaeva et al., 2000). However, little is known about methods for nuclear transfer in horses. In contrast to other species, there are no reports on equine nuclear transfer using embryonic blastomeres, due to the difficulty of recovering early embryos in vivo and the failure of IVF to be successful reproducibly in this species. Somatic cell nuclear transfer has been investigated in horses only recently (Hinrichs et al., 2000; Li et al., 2000a; Reggio et al., 2000; Choi et al., 2001). Hinrichs et al. (2000) found that the activation rate of equine oocytes was low (3/28, 11\%,

*Correspondence

Email: khinrichs@cvm.tamu.edu estimated by cleavage rates) compared with that for bovine oocytes $(49 / 93,53 \%)$ after transfer of equine somatic cells. Cleavage rates after nuclear transfer in equine oocytes were also low in two other studies (0/24: Reggio et al., 2000; and 1/7 (14\%): Li et al., 2000a).

Activation of host cytoplasts is a crucial step in the production of embryos by nuclear transfer (Mitalipov et al., 1999; Polejaeva et al., 2000). Two studies have compared methods for activation of equine oocytes (Hinrichs et al., 1995a; Li et al., 2000b). Hinrichs et al. (1995a) treated cumulus-enclosed oocytes with $5-7 \%(\mathrm{v} / \mathrm{v})$ ethanol or 5-10 $\mu \mathrm{mol}$ calcium ionophore A23187 $\mathrm{I}^{-1}$ in combination with cycloheximide, and obtained an estimated $11-70 \%$ activation rate per metaphase II oocyte. Activation rates for oocytes that originally had expanded cumuli were significantly higher than the activation rates of oocytes that originally had compact cumuli. Li et al. (2000b) obtained $56-79 \%$ activation rates (resumption of meiosis or decondensation of the sperm head) after intracytoplasmic sperm injection (ICSI) and treatment of oocytes with 
$10 \mu \mathrm{mol}$ ionomycin $\mathrm{l}^{-1}, 7 \% \quad(\mathrm{v} / \mathrm{v})$ ethanol, $100 \mu \mathrm{mol}$ thimerosal $\mathrm{I}^{-1}$ or injections of $250 \mu \mathrm{mol}$ inositol 1,4,5trisphosphate $\left.\right|^{-1}$. The highest rate of female pronucleus formation/first mitosis in that study was 56\%. Activation rates after ICSI, estimated by cleavage or pronuclear formation, were similar after treatment with $10 \mu \mathrm{mol}$ calcium ionophore $\mathrm{I}^{-1}$ for $5 \mathrm{~min}$ (27-48\%: Kato et al., 1997; Schmid et al., 2000) or with no activation treatment (54-63\%; Dell'Aquila et al., 1999). In pig oocytes, increases in concentration of calcium ionophore from 10 to $50 \mu \mathrm{mol} \mathrm{I}^{-1}$ were associated with increased rates of nuclear activation (Wang et al., 1998); however, no work has been done with concentrations of calcium ionophore $>10 \mu \mathrm{mol} \mathrm{I}^{-1}$ in equine oocytes.

Mature oocytes are arrested in metaphase II in association with a high activity p34 ${ }^{\mathrm{cdc} 2}$-cyclin B complex (maturation-promoting factor; MPF). MPF activity is maintained during metaphase II arrest by the activity of cytostatic factor, which prevents the degradation of the cyclin B component (O'Keefe et al., 1991). Cytostatic factor activity is dependent on the activity of the c-mos protein, its substrate mitogen-activation protein (MAP) kinase kinase and its substrate, MAP kinase (O'Keefe et al., 1991; Cross and Smythe, 1998). Oocyte activation, marked by completion of meiosis and formation of the female pronucleus, is induced by multiple oscillations of intracellular free calcium $\left(\mathrm{Ca}^{2+}\right)$ during fertilization. The increase in $\mathrm{Ca}^{2+}$ induces inactivation of MPF and subsequently of cytostatic factor. Calcium ionophore is also able to induce an increase in cytoplasmic $\mathrm{Ca}^{2+}$ concentration and, thus, may serve to activate oocytes parthenogenetically. However, if the oocyte is still actively synthesizing protein, it appears to replenish the activity of cytostatic factor, which causes a recrudescence of MPF activity, thus holding oocytes at 'metaphase III' (Liu and Yang, 1999). Treatment with cycloheximide, which blocks synthesis of proteins, can prevent MPF reactivation after an initial calcium influx (Presicce and Yang, 1994; Yang et al., 1994; Moos et al., 1996). When cycloheximide is used in combination with activating stimuli such as ethanol, calcium ionophore or an electric pulse, synergistic effects on activation have been reported in bovine (Shi et al., 1993; Presicce and Yang, 1994; Yang et al., 1994; Liu et al., 1998), pig (Jilek et al., 2000) and equine (Hinrichs et al., 1995a) oocytes.

Follicular fluid has been added to maturation media to support cytoplasmic maturation, as assessed by pronucleus formation and embryonic development after IVF, in pigs (Naito et al., 1988; Yoshida et al., 1992; Vatzias and Hagen, 1999), sheep (Sun et al., 1994) and cattle (Kim et al., 1996; Romero-Arredondo and Seidel, 1996). In horses, Dell'Aquila et al. (1997) reported a positive effect of $20 \%(\mathrm{v} / \mathrm{v})$ follicular fluid during maturation on rates of pronucleus formation after ICSI of oocytes. Culture of equine oocytes in $100 \%$ follicular fluid yielded higher rates of fertilization after IVF than did culture in medium with added serum or added follicular fluid (K. Hinrichs, D. D. Varner and C. C. Love, unpublished). The present study was conducted to examine the effects of maturation medium, calcium ionophore concentration and duration of cycloheximide culture on activation of cumulus-free equine oocytes.

\section{Materials and Methods}

\section{Preparation of follicular fluid}

Mares in oestrus with a preovulatory follicle $>33 \mathrm{~mm}$ in diameter were treated with hCG (2000 iu, i.v.). After 24 h, follicular fluid was aspirated from the follicle by flank puncture (Vogelsang et al., 1988). The granulosa cells recovered were examined under a dissection microscope and only fluid from follicles yielding expanded granulosa cells, indicative of response to hCG (Hinrichs et al., 1998), was used for the experiment. The follicular fluid was centrifuged immediately at $2800 \mathrm{~g}$ for $10 \mathrm{~min}$ at room temperature, decanted, frozen in aliquots and kept at $-20^{\circ} \mathrm{C}$ until used.

\section{Oocyte collection}

Ovaries were transported in PBS from local abattoirs to the laboratory (3-4 $\mathrm{h}$ transport time). The ovaries were trimmed with scissors and cleaned with sterilized gauze. All visible follicles were opened with a scalpel blade and the granulosa layer of each follicle was scraped using a $0.5 \mathrm{~cm}$ bone curette. The contents of the curette were washed into individual Petri dishes with Hepes-buffered TCM-199 with Hank's salts (Gibco Life Technologies Inc, Grand Island, NY) plus ticarcillin $\left(0.1 \mathrm{mg} \mathrm{m}^{-1}\right.$; SmithKline Beecham Pharmaceuticals, Philadelphia, PA). The contents of the Petri dishes were examined using a dissection microscope at $\times 10-20$ magnification. Cumulus-oocyte complexes were classified as compact, expanded or degenerating depending on the expansion of both mural granulosa and cumulus as described previously (Hinrichs and Williams, 1997; Hinrichs and Schmidt, 2000). Oocytes with any sign of expansion of either the cumulus or the mural granulosa (from having individual cells visible protruding from the surface to having full expansion with copious matrix visible between cells) were classified as expanded. Oocytes with both compact cumulus and compact mural granulosa were classified as compact. Only expanded oocytes were used for activation treatments.

\section{In vitro maturation}

Selected oocytes were washed twice in either maturation medium (TCM-199 with Earle's salts (Gibco), $5 \mu \mathrm{U}$ FSH ml ${ }^{-1}$ (Schering, Kenilworth, NJ), 10\% fetal bovine serum (FBS) and $25 \mu \mathrm{g}$ gentamycin $\mathrm{ml}^{-1}$ ) or in $100 \%$ follicular fluid. Oocytes were cultured in droplets of the corresponding medium or fluid $(10 \mu \mathrm{l}$ per oocyte) under light white mineral oil (Sigma Chemical Co, St Louis, MO) at $38.2^{\circ} \mathrm{C}$ in $5 \% \mathrm{CO}_{2}$ in air for $40-42 \mathrm{~h}$. 


\section{Activation treatment}

After culture, oocytes were denuded of cumulus cells by pipetting in TCM-199 with Hank's salts and $25 \mathrm{mmol}$ Hepes $\mathrm{I}^{-1}$ (Gibco) with 10\% FBS, mixed 50:50 with 0.1\% (w/v) hyaluronidase (Sigma) in Hank's salt solution (Gibco). Oocytes with an intact cytoplasmic membrane were selected and put into TCM-199 with Hank's salts and $25 \mathrm{mmol}$ Hepes $\mathrm{I}^{-1}$ supplemented with $20 \%$ FBS. The oocytes were washed twice in modified PBS without protein and treated with 10 or $50 \mu \mathrm{mol}$ calcium ionophore $\mathrm{A}$ $23187 \mathrm{I}^{-1}$ (Sigma) in PBS at $37^{\circ} \mathrm{C}$ for $5 \mathrm{~min}$. The stock solution of calcium ionophore was $10 \mathrm{mmol} \mathrm{I}^{-1}$ in dimethylsulphoxide and was kept at $-20^{\circ} \mathrm{C}$ until used. After calcium ionophore treatment, the oocytes were washed in TCM-199 containing 20\% FBS and assigned to one of three treatments: (i) culture in TCM-199 with Earle's salts, containing $10 \%$ FBS and $10 \mu \mathrm{g}$ cycloheximide $\mathrm{ml}^{-1}$ (Sigma), for $6 \mathrm{~h}$ followed by fixation and staining; (ii) similar culture in cycloheximide-containing medium for $24 \mathrm{~h}$; or (iii) culture in the cycloheximide-containing medium for $6 \mathrm{~h}$ followed by washing and culture in the same medium but without cycloheximide for $18 \mathrm{~h}$ (6 h plus $18 \mathrm{~h}$ ).

Concurrent with the above experiment, equine oocytes were matured for $42 \mathrm{~h}$ in follicular fluid, and then cultured for an additional $24 \mathrm{~h}$ in the presence of supernatant from a sperm preparation to evaluate the rate of spontaneous activation.

\section{Selection for membrane integrity}

One hundred and sixty-three oocytes with compact cumuli were cultured in maturation medium for $24 \mathrm{~h}$ to determine the efficiency of selecting metaphase II oocytes on the basis of membrane integrity after maturation. After denuding the cumulus, oocytes were selected either for membrane integrity (possession of a clearly defined, smooth membrane around the ooplasm) or for the presence of an apparent polar body.

\section{Evaluation of oocytes}

For evaluation, oocytes were fixed briefly in buffered formal saline and placed on a glass slide with $6.5 \mu \mathrm{l}$ mounting medium (3:1 glycerol:PBS containing $2.5 \mu \mathrm{g}$ Hoechst $33258 \mathrm{ml}^{-1}$ ). The sample was examined using an epifluorescence microscope with a $365 \mathrm{~nm}$ excitation filter. Oocytes were classified as described in cows (Presicce and Yang, 1994) and horses (Li et al., 2000b) as metaphase, pronucleus I-II (dense to decondensing chromatin), pronucleus III-IV (decondensed chromatin) or as progressing toward the first cleavage division as marked by bivalents condensed within the pronuclear area (Fig. 1). Other chromatin configurations (dispersed chromatin, abnormal chromatin or no chromatin) were considered as degenerated. Oocytes in metaphase were grouped together regardless of the number of polar bodies observed, as the ability to visualize the equine polar body in metaphase II oocytes
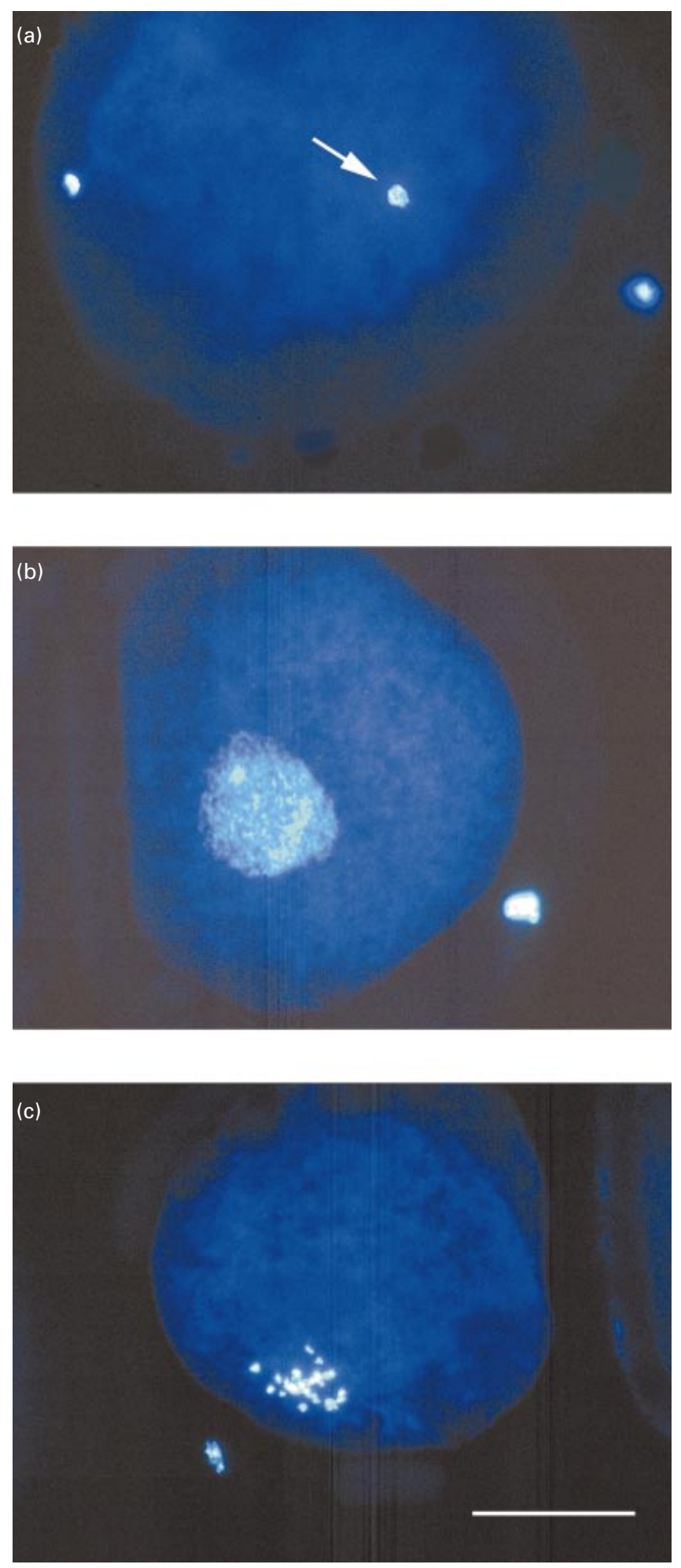

Fig. 1. Activation of equine oocytes with calcium ionophore and cycloheximide. (a) Pronucleus (pronuclear I; dense chromatin, arrow) with two polar bodies. (b) Pronucleus (pronuclear IV) with polar body. (c) Progression toward the first mitotic division (condensation of bivalents) with polar body. Scale bar represents $50 \mu \mathrm{m}$. 
Table 1. Chromatin configuration of equine oocytes after activation treatment

\begin{tabular}{|c|c|c|c|c|c|c|c|c|c|c|c|c|}
\hline \multirow{3}{*}{$\begin{array}{l}\text { Maturation medium } \\
\text { Calcium ionophore }\left(\mu \mathrm{mol} \mathrm{I}^{-1}\right) \\
\text { Culture time (h) }\end{array}$} & \multicolumn{6}{|c|}{ Follicular fluid } & \multicolumn{6}{|c|}{ TCM-199 } \\
\hline & \multicolumn{3}{|c|}{10} & \multicolumn{3}{|c|}{50} & \multicolumn{3}{|c|}{10} & \multicolumn{3}{|c|}{50} \\
\hline & $6^{a}$ & $6+18^{b}$ & $24^{c}$ & $6^{\mathrm{a}}$ & $6+18^{b}$ & $24^{c}$ & $6^{\mathrm{a}}$ & $6+18^{b}$ & $24^{c}$ & $6^{\mathrm{a}}$ & $6+18^{b}$ & $24^{c}$ \\
\hline Treated $(n)$ & 34 & 35 & 27 & 31 & 31 & 26 & 40 & 35 & 32 & 39 & 34 & 34 \\
\hline Degenerated $(n)$ & 6 & 1 & 2 & 0 & 2 & 2 & 1 & 1 & 3 & 1 & 3 & 1 \\
\hline Basis $(n)$ & 28 & 34 & 25 & 31 & 29 & 24 & 39 & 34 & 29 & 38 & 31 & 33 \\
\hline \multicolumn{13}{|l|}{ Nuclear stage } \\
\hline Pronuclear I-II (\%) & $6(21)$ & $0(0)$ & $3(12)$ & $3(10)$ & $1(3)$ & $3(13)$ & $1(3)$ & $0(0)$ & $0(0)$ & $5(13)$ & $0(0)$ & $2(6)$ \\
\hline Pronuclear III-IV (\%) & $2(7)$ & $14(41)$ & $5(20)$ & $2(6)$ & $4(14)$ & $7(29)$ & $3(8)$ & $3(9)$ & $9(31)$ & $16(42)$ & $10(32)$ & $17(52$ \\
\hline First mitosis (\%) & $1(4)$ & $0(0)$ & $7(28)$ & $0(0)$ & $0(0)$ & $2(8)$ & $3(8)$ & $3(9)$ & $11(38)$ & $2(5)$ & $6(19)$ & $8(24$ \\
\hline Total activated $(\%)$ & $9(32)$ & $14(41)$ & $15(60)$ & $5(16)$ & $5(17)$ & $12(50)$ & $7(18)$ & $6(18)$ & $20(69)$ & $23(61)$ & $16(52)$ & $27(82$ \\
\hline Metaphase (\%) & $19(68)$ & $20(59)$ & $10(40)$ & $26(84)$ & $24(83)$ & $12(50)$ & $32(82)$ & $28(82)$ & $9(31)$ & $15(39)$ & $15(48)$ & $6(18$ \\
\hline
\end{tabular}

Calcium ionophore: A23187; treated: number of oocytes treated; degenerated: oocytes with degenerating chromatin at the time of staining; basis: oocytes that were not degenerated at the time of staining (presumed metaphase II at the time of activation).

${ }^{a}$ Culture in cycloheximide-containing medium for $6 \mathrm{~h}$.

${ }^{b}$ Culture with cycloheximide for $6 \mathrm{~h}$ then $18 \mathrm{~h}$ further culture with no cycloheximide.

${ }^{c}$ Culture with cycloheximide for $24 \mathrm{~h}$.

Pronuclear I-II: dense to decondensing chromatin; pronuclear III-IV: decondensed chromatin (pronucleus).

decreases as the duration of culture increases (Gable and Woods, 1999).

\section{Statistical analysis}

Each activation treatment was replicated three times. The two media and two calcium ionophore treatments were repeated on every collection day; however, only one culture treatment was performed on a given day. The proportions of oocytes with intact cytoplasmic membranes after maturation were compared using chi-squared analysis. Activation rates were determined on the basis of activated oocytes plus non-activated (metaphase) oocytes; oocytes with degenerating chromatin were disregarded.

A logistic regression model was used to analyse the main effects of media, calcium ionophore treatment and culture treatment, in addition to the three two-way interactions and the three-way interaction (Liang and Zeger, 1986). The model used generalized estimating equations to account for any within-day correlation that may have been attributable to factors not included in the model. Statistical testing was performed using the likelihood ratio chi-squared test. The level of significance was $P<0.05$.

\section{Results}

Seventy-nine oocytes with compact cumuli were cultured, and 23 oocytes were selected as having an intact, smooth cytoplasmic membrane. Twenty-one (91\%) of the selected oocytes were found to be in metaphase II upon staining and evaluation. Two of 56 rejected oocytes (4\%) were found to be in metaphase II. An additional 84 oocytes with compact cumuli were cultured, and 26 oocytes were selected for the presence of a polar body. Twenty-three (89\%) of these oocytes were found to be in metaphase II upon staining and evaluation. Two of 58 oocytes in which no polar body was visible (4\%) were found to be in metaphase II after staining.

For the activation study, 1858 follicles were scraped and 1065 oocytes were collected, for a recovery rate of $57 \%$. Of the cumulus- oocyte complexes collected, 672 were expanded, 344 were compact and 49 were degenerating at the time of recovery. For this experiment, 621 expanded oocytes were used. The percentages of oocytes with an intact cytoplasmic membrane after maturation were $76 \%$ $(241 / 317)$ in TCM-199 and 70\% (213/304) in follicular fluid. This difference was not significant. After activation, one FSH replicate (27 oocytes) was discarded due to contamination and one follicular fluid replicate (20 oocytes) was discarded because of a break in protocol (use of the wrong batch of follicular fluid).

The percentages of oocytes in the different chromatin stages after activation treatment are shown (Table 1). The proportion of activation-treated oocytes categorized as degenerating after staining was not significantly different between maturation media (10/214 (5\%) for TCM-199 and $13 / 184(7 \%)$ for follicular fluid). Activation rates are expressed as a proportion of the oocytes presumed to be in metaphase II at the time of treatment (disregarding degenerating oocytes). The activation rate for oocytes matured in TCM-199 was significantly higher than that for oocytes matured in follicular fluid (99/204 (49\%) versus $60 / 171$ (35\%), respectively; $P<0.05)$. Culture with cycloheximide for $24 \mathrm{~h}$ resulted in a significantly higher rate of activation $(67 \%$; $74 / 111)$ than did the $6 \mathrm{~h}(33 \%$; 44/136) or $6 \mathrm{~h}$ plus $18 \mathrm{~h}(32 \% ; 41 / 128)$ treatments. There was no overall difference in activation rates between $10 \mu \mathrm{mol} \mathrm{I}^{-1}$ (38\%; 71/189) and $50 \mu \mathrm{mol} \mathrm{I}^{-1}(47 \% ; 88 / 186)$ calcium ionophore treatments, but there was a significant interaction between maturation medium and calcium ionophore treatment $(P<0.01)$. TCM-199-matured oocytes exposed to 
cycloheximide for $6 \mathrm{~h}$ (the $6 \mathrm{~h}$ and $6 \mathrm{~h}$ plus $18 \mathrm{~h}$ groups) had significantly higher activation rates when treated with $50 \mu \mathrm{mol}$ calcium ionophore $\mathrm{I}^{-1}$ than when treated with $10 \mu \mathrm{mol}$ calcium ionophore $\mathrm{I}^{-1}(P<0.001)$. The highest activation rate $(82 \%)$ was observed in oocytes matured in TCM-199 and activated with $50 \mu \mathrm{mol}$ calcium ionophore $\mathrm{I}^{-1}$ followed by cycloheximide treatment for $24 \mathrm{~h}$. This activation rate tended to be higher than that for TCM-199 maturation, $10 \mu \mathrm{mol}$ calcium ionophore $\mathrm{I}^{-1}$, and $24 \mathrm{~h}$ cycloheximide treatment $(P=0.059)$, and was significantly higher than that for all other treatments.

One of 71 oocytes cultured for $42 \mathrm{~h}$ in follicular fluid and then an additional $24 \mathrm{~h}$ after addition of sperm suspension supernatant $(1 \%)$ had a pronucleus when evaluated after fixation and staining.

\section{Discussion}

The medium used during in vitro maturation is a key factor in preparation of oocytes for subsequent embryo development (Mermillod et al., 1999; Kruip et al., 2000). Follicular fluid has been used in two different ways to promote cytoplasmic maturation of oocytes: to suppress meiosis in medium without gonadotrophins, while cytoplasmic maturation proceeds (Sirard et al., 1992), or to enhance cytoplasmic development during maturation through supplementation of gonadotrophin-containing media (Naito et al., 1988). In equine oocytes, $100 \%$ follicular fluid, even that recovered from viable immature follicles, does not suppress meiosis (Hinrichs et al., 1995b). In the present study, the hypothesis that follicular fluid from viable preovulatory follicles collected approximately $12 \mathrm{~h}$ before ovulation $(24 \mathrm{~h}$ after hCG stimulation) would support both nuclear and cytoplasmic maturation of the oocytes was tested.

Equine oocytes that do not mature in culture appear to degenerate, as the proportion remaining in the germinal vesicle stage after culture is negligible (Alm and Hinrichs, 1995). Therefore, evaluation of oocytes for an intact cytoplasmic membrane was used in the present study to select for metaphase II oocytes before activation. Selection for membrane integrity has similar efficiency to selection for presence of an apparent polar body in equine oocytes. Selection of oocytes for the presence of an intact cytoplasmic membrane in the activation study was effective in selecting for metaphase oocytes, as overall only 23 of 398 $(6 \%)$ oocytes selected in this way had degenerating chromatin upon staining; the remaining oocytes were in metaphase II or were activated. Neither the percentages of oocytes with an intact cytoplasmic membrane $(70 \%$ for follicular fluid versus $76 \%$ for TCM-199) nor the proportions of degenerating oocytes after activation and staining (7\% for follicular fluid and 5\% for TCM-199) were different between media treatments. The overall maturation rate, (the proportion of metaphase or activated oocytes observed after staining), taken as a percentage of all oocytes put into maturation medium, was $65 \%$ for follicular fluid and $72 \%$ for TCM-199.
Although nuclear maturation rates were comparable in TCM-199 and follicular fluid, culture in TCM-199 yielded oocytes that were activated more easily by calcium ionophore treatments than the oocytes matured in follicular fluid. This finding is interesting in view of a recent report on the rate of fertilization and early embryo development of in vitro-matured oocytes after transfer to the oviduct of inseminated mares (Love et al., 2000). In that study, oocytes matured in $100 \%$ follicular fluid had similar fertilization rates, but lower embryo development rates, than did oocytes matured in TCM-199. Taken together, these data indicate that cytoplasmic maturation may be somehow impaired after in vitro maturation in $100 \%$ follicular fluid.

Follicular fluid recovered $24 \mathrm{~h}$ after hCG administration would be expected to have all the hormonal signals present to support normal cytoplasmic maturation. Equine oocytes in vivo progress to metaphase I by $24 \mathrm{~h}$ after hCG administration (Bezard et al., 1997). One major difference between the follicular fluid and TCM-199 treatments is that follicular fluid may have a low concentration of FSH, as the peripheral concentrations of $\mathrm{FSH}$ are at their nadir at the time that the preovulatory follicle reaches its maximum diameter immediately before ovulation (Snyder et al., 1979). It is possible that some direct effect of the FSH added to the TCM-199 may be responsible for the responsiveness of these oocytes. Cumulus-oocyte complexes removed from follicles in an immature state may need FSH stimulation to trigger normal cytoplasmic maturation, either directly or through formation of receptors for factors present in the fluid.

Differences between the suppression of activation by follicular fluid observed in the present study and enhancement of normal fertilization observed in other experiments (Dell'Aquila et al., 1997) may be due to the proportion of follicular fluid used $(100 \%$ in the present study) or to the nature of the activation stimulus. In ICSI or conventional IVF, the spermatozoa induce serial calcium transients. However, parthenogenetic activation is induced by one calcium transient (for example, calcium ionophore or ionomycin) followed by suppression of MPF after activation by inhibitors of protein kinase activation, such as cycloheximide or 6-dimethyl amino purine (Susko-Parrish et al., 1994; Hinrichs et al., 1995a; Liu et al., 1998). It is possible that the failure of oocytes matured in follicular fluid to respond to the activation stimulus is in fact a sign of vigour; that is, that the MPF concentrations are higher or replenished more rapidly in these oocytes. Further study on the comparison of MPF concentrations in oocytes matured in the different media would be of interest.

The oocytes used as controls in the present study showed a low rate of spontaneous activation (1/71) in agreement with previously reported findings (spontaneous activation rate for equine oocytes of 4-5\%: Hinrichs et al., 1995a; 0\%: Dell'Aquila et al., 1999; and 0\%: Li et al., 2000b).

In pig oocytes, increasing calcium ionophore concentration from 10 to $50 \mu \mathrm{mol} \mathrm{^{-1 }}$ resulted in higher nuclear activation rates (Wang et al., 1998). The increase in acti- 
vation was associated with a greater $\mathrm{Ca}^{2+}$ influx achieved with the higher concentration of ionophore. In the present study, activation rates of TCM-199-matured oocytes treated with $50 \mu \mathrm{mol}$ calcium ionophore $\mathrm{I}^{-1}$ tended to be higher than those for $10 \mu \mathrm{mol}$ calcium ionophore $\mathrm{I}^{-1}$, and in those groups exposed to cycloheximide for only $6 \mathrm{~h}$, activation rates were significantly higher in the $50 \mu \mathrm{mol} \mathrm{I}^{-1}$ group. This finding indicates that a higher initial calcium transient may induce more profound inhibition of MPF activity, thus overcoming the need for prolonged exposure to cycloheximide for an effective decrease in MPF concentrations in equine oocytes.

$\mathrm{Li}$ et al. (2000b) used thimerosal to activate equine oocytes after ICSI to mimic the calcium transients of fertilization. Thimerosal induces multiple intracellular calcium transients in unfertilized mammalian oocytes by promoting inositol 1,4,5-triphosphate-induced intracellular calcium release (Swann, 1991; Fissore and Robl, 1993). Li et al. (2000b) matured the equine oocytes in TCM-199 with added FSH, LH and oestradiol, and 20\% FBS. A 79\% activation rate (resumption of meiosis) was obtained using thimerosal; however, only $39 \%$ of oocytes formed a female pronucleus and an additional $7 \%$ were in the first mitotic division after treatment. The rates of these stages in the most effective treatment in the present study (maturation in TCM199, activation with $50 \mu \mathrm{mol}$ calcium ionophore $\mathrm{I}^{-1}$ and cycloheximide incubation for $24 \mathrm{~h}$ ) were $52 \%$ (formation of female pronucleus) and $24 \%$ (first mitotic division). This finding indicates that inhibition of cytostatic factor activity after activation may be more effective in equine oocytes than induction of multiple calcium oscillations.

In cattle, ethanol-treated oocytes fixed after only $3 \mathrm{~h}$ exposure to cycloheximide had high rates of activation (96\%, Presicce and Yang, 1994); however, low rates of activation were obtained in preliminary trials when equine oocytes were exposed to cycloheximide for only $6 \mathrm{~h}$ (K. Hinrichs, unpublished). As good activation rates have been obtained after culture of equine oocytes with cycloheximide for $24 \mathrm{~h}$ (Hinrichs et al., 1995a), we wished to determine whether the important factor in activation was duration of exposure to cycloheximide, or simply increased duration of culture. The results of the present study indicate that $24 \mathrm{~h}$ incubation with cycloheximide after activation treatment of equine oocytes produces a higher activation rate than does $6 \mathrm{~h}$ exposure, even if the $6 \mathrm{~h}$ exposure is followed by additional culture time (as seen in the $6 \mathrm{~h}$ plus $18 \mathrm{~h}$ treatment). The requirement for relatively intense stimuli (high calcium ionophore concentrations and long duration of cycloheximide exposure) to achieve activation in equine oocytes, especially in light of low rates of spontaneous activation (Hinrichs et al., 1995a; Dell'Aquila et al., 1999; Li et al., 2000b; present study) and low activation rates after nuclear transfer (Hinrichs et al., 2000; Li et al., 2000a; Reggio et al., 2000) indicate that metaphase II equine oocytes have robust mechanisms for maintaining high MPF activity.

When germinal vesicle stage oocytes are cultured with cycloheximide, chromosomes form bivalents inside the intact germinal vesicle membrane (Kubelka et al., 1995). Long-term cycloheximide treatment appeared to have a similar effect on the activated oocytes in the present study. Thus, although long term culture with cycloheximide $(24 \mathrm{~h}$ after activation treatment) had a positive effect on parthenogenetic activation, the effect on developmental capability of nuclear transferred or intracytoplasmic sperm injected oocytes should be investigated further.

In conclusion, equine oocytes matured in TCM-199 with serum and $\mathrm{FSH}$ for 40-42 $\mathrm{h}$ may be activated effectively with $50 \mu \mathrm{mol}$ calcium ionophore $\mathrm{I}^{-1}$ followed by incubation with cycloheximide for $24 \mathrm{~h}$. This may be a useful protocol for activation after cloning or ICSI.

This work was supported by the Link Equine Research Endowment Fund, Texas A\&M University. The authors would like to thank L. B. Love for excellent technical assistance.

\section{References}

Alm H and Hinrichs K (1996) Effect of cycloheximide on nuclear maturation of horse oocytes and its relation to initial cumulus morphology Journal of Reproduction and Fertility $107215-220$

Baguisi A, Behboodi E, Melican DT et al. (1999) Production of goats by somatic cell nuclear transfer Nature Biotechnology 17 456-461

Bezard J, Mekarska A, Goudet G, Duchamp G and Palmer E (1997) Timing of in vivo maturation of equine preovulatory oocytes and competence for in vitro maturation of immature oocytes collected simultaneously Equine Veterinary Journal Supplement 25 33-37

Choi YH, Shin T, Love CC, Burghardt RC, Varner DD and Hinrichs K (2001) Effects of initial cumulus morphology and addition of cytochalasin B on fusion, activation and cleavage of horse oocytes undergoing nuclear transfer Theriogenology 55261 (Abstract)

Cross DAE and Smythe C (1998) PD 98059 prevents establishment of the spindle assembly checkpoint and inhibits the $\mathrm{G}_{2}-\mathrm{M}$ transition in meiotic but not mitotic cell cycles in Xenopus. Experimental Cell Research 241 12-22

Dell'Aquila ME, Cho YS, Minoia P, Traina V, Lacalandra GM and Maritato $\mathbf{F}$ (1997) Effects of follicular fluid supplementation of in-vitro maturation medium on the fertilization and development of equine oocytes after in-vitro fertilization or intracytoplasmic sperm injection Human Reproduction 12 2766-2772

Dell'Aquila ME, De Felici M, Massari S, Maritato F and Minoia P (1999) Effects of fetuin on zona pellucida hardening and fertilizability of equine oocytes matured in vitro. Biology of Reproduction 61 533-540

Fissore RA and Robl JM (1993) Sperm, inositol trisphosphate and thimerosal-induced intracellular $\mathrm{Ca}^{2+}$ elevations in rabbit eggs Developmental Biology 159 122-130

Gable TL and Woods GL (1999) Increased culture time increases nuclear development of equine oocytes Biology of Reproduction Supplement $\mathbf{6 0}$ 184 (Abstract)

Hinrichs K and Schmidt AL (2000) Meiotic competence in horse oocytes: interactions among chromatin configuration, follicle size, cumulus morphology, and season Biology of Reproduction 62 1402-1408

Hinrichs K and Williams KA (1997) Relationships among oocyte-cumulus morphology, follicular atresia and oocyte meiotic competence in the horse Biology of Reproduction 57 377-384

Hinrichs K, Schmidt AL and Selgrath JP (1995a) Activation of horse oocytes Biology of Reproduction Monograph Series 1 319-324

Hinrichs K, Martin MG, Schmidt AL and Friedman PP (1995b) Effect of follicular components on meiotic arrest and resumption in horse oocytes Journal of Reproduction and Fertility 104 149-156

Hinrichs K, Matthews GL, Freeman DA and Torello EM (1998) Oocyte transfer in mares Journal of American Veterinary Medical Association 212 982-986 
Hinrichs K, Shin T, Love CC, Varner DD and Westhusin ME (2000) Comparison of bovine and equine oocytes as host cytoplasts for equine nuclear transfer Proceedings of the $5^{\text {th }}$ International Symposium on Equine Embryo Transfer, Saari, Finland pp 43-44 Eds T Katila and J Wade (Abstract)

Jilek F, Huttelova R, Petr J, Holubova M and Rozinek J (2000) Activation of pig oocytes using calcium ionophore: effect of protein synthesis inhibitor cycloheximide Animal Reproduction Science 63 101-111

Kato H, Seidel GE, Squires EL and Wilson JM (1997) Treatment of equine oocytes with A23187 after intracytoplasmic sperm injection Equine Veterinary Journal Supplement 25 51-53

Kato Y, Tani T, Sotomaru Y, Kurokawa K, Kato J, Doguchi H, Yasue H and Tsunoda Y (1998) Eight calves cloned from somatic cells of a single adult Science 282 2095-2098

Kim KS, Mitsumizo N, Fujita K and Utsumi K (1996) The effects of follicular fluid on in vitro maturation, oocyte fertilization and the development of bovine embryos Theriogenology 45 787-799

Kruip TAM, Bevers MM and Kemp B (2000) Environment of oocyte and embryo determines health of IVP offspring Theriogenology 53 611-618

Kubelka M, Rimkevicova Z, Guerrier P and Motlik J (1995) Inhibition of protein synthesis affects histone $\mathrm{H} 1$ kinase, but not chromosome condensation activity, during the first meiotic division of pig oocytes Molecular Reproduction and Development 41 63-69

Li X, Morris LHA and Allen WR (2000a) Chromatin reprogramming in enucleated horse oocytes injected with cumulus cell nuclei Journal of Reproduction and Fertility Abstract Series $\mathbf{2 5} 77$

Li X, Morris LHA and Allen WR (2000b) Effects of different activation treatments on fertilization of horse oocytes by intracytoplasmic sperm injection Journal of Reproduction and Fertility 119 253-260

Liang K-Y and Zeger SL (1986) Longitudinal data analysis using generalized linear models Biometrika 73 13-22

Liu L and Yang X (1999) Interplay of maturation-promoting factor and mitogen-activated protein kinase inactivation during metaphase-tointerphase transition of activated bovine oocytes Biology of Reproduction 61 1-7

Liu L, Ju JC and Yang X (1998) Parthenogenetic development and protein patterns of newly matured bovine oocytes after chemical activation Molecular Reproduction and Development 49 298-307

Love CC, Brinsko SP, Varner DD and Hinrichs K (2000) Fertilization rates of in vitro-matured oocytes transferred into the oviduct of inseminated mares Proceedings of the $5^{\text {th }}$ International Symposium on Equine Embryo Transfer, Saari, Finland pp 41-42 Eds T Katila and J Wade (Abstract)

Mermillod P, Oussaid B and Cognie Y (1999) Aspects of follicular and oocyte maturation that affect the developmental potential of embryos Journal of Reproduction and Fertility Supplement 54 449-460

Mitalipov SM, White KL, Farrar VR, Morrey J and Reed WA (1999) Development of nuclear transfer and parthenogenetic rabbit embryos activated with inositol 1,4,5-trisphosphate Biology of Reproduction 60 821-827

Moos J, Kopf GS and Schultz RM (1996) Cycloheximide-induced activation of mouse eggs: effects on cdc2/cyclin B and MAP kinase activities Journal of Cell Science 109 739-748

Naito K, Fukuda Y and Toyoda Y (1988) Effects of porcine follicular fluid on male pronucleus formation in porcine oocytes matured in vitro. Gamete Research 21 289-295

O'Keefe SJ, Kiessling AA and Cooper GM (1991) The c-mos gene product is required for cyclin $B$ accumulation during meiosis of mouse eggs Proceedings National Academy of Sciences USA 88 7869-7872

Onishi A, Iwamoto M, Akita T, Mikawa S, Takeda K, Awata T, Hanada H and Perry ACF (2000) Pig cloning by microinjection of fetal fibroblast nuclei Science 289 1188-1190

Polejaeva IA, Chen SH, Vaught TD et al. (2000) Cloned pigs produced by nuclear transfer from adult somatic cells Nature 407 86-90

Presicce GA and Yang X (1994) Nuclear dynamics of parthenogenesis of bovine oocytes matured in vitro for 20 and 40 hours and activated with combined ethanol and cycloheximide treatment Molecular Reproduction and Development 37 61-68

Reggio BC, Cochran RA, Guitreau A, Carter JA, Denniston RS and Godke RA (2000) Nuclear transfer embryos in the horse Proceedings of the $5^{\text {th }}$ International Symposium on Equine Embryo Transfer, Saari, Finland pp 45-46 Eds T Katila and J Wade (Abstract)

Romero-Arredondo A and Seidel GE, Jr (1996) Effects of follicular fluid during in vitro maturation of bovine oocytes on in vitro fertilization and early embryonic development Biology of Reproduction 55 1012-1016

Schmid RL, Kato H, Herickhoff LA, Shenk JL, McCue PM, Chung YG and Squires EL (2000) Effects of follicular fluid or progesterone on in vitro maturation of equine oocytes before intracytoplasmic sperm injection with non-sorted and sex-sorted spermatozoa Journal of Reproduction and Fertility Supplement $\mathbf{5 6}$ 519-525

Shi Z, Jiang S and Yang X (1993) Synergistic effect of A23187 and cycloheximide allows effective activation of freshly matured bovine oocytes Theriogenology 39303 (Abstract)

Sirard MA, Coenen K and Bilodeau S (1992) Effect of fresh or cultured follicular fractions on meiotic resumption in bovine oocytes Theriogenology 37 39-57

Snyder DA, Turner DD, Miller KF, Garcia MC and Ginther OJ (1979) Follicular and gonadotrophic changes during transition from ovulatory to anovulatory seasons Journal of Reproduction and Fertility Supplement 27 95-101

Sun FJ, Holm P, Irvine B and Seamark RF (1994) Effect of sheep and human follicular fluid on the maturation of sheep oocytes in vitro. Theriogenology $\mathbf{4 1}$ 981-988

Susko-Parrish JL, Leibfried-Rutledge ML, Northey DL, Shutzkus V and First NL (1994) Inhibition of protein kinases after an induced calcium transient causes transition of bovine oocytes to embryonic cycles without meiotic completion Developmental Biology 166 729-739

Swann K (1991) Thimerosal causes calcium oscillations and sensitizes calcium-induced calcium release in unfertilized hamster eggs FEBS Letters 278 175-178

Vatzias G and Hagen DR (1999) Effects of porcine follicular fluid and oviduct-conditioned media on maturation and fertilization of porcine oocytes in vitro. Biology of Reproduction $6042-48$

Vogelsang MM, Kreider JL, Bowen MJ, Potter GD, Forrest DW and Kraemer DC (1988) Methods for collecting follicular oocytes from mares Theriogenology 29 1007-1018

Wakayama T, Perry ACF, Zuccotti M, Johnson KR and Yanagimachi R (1998) Full-term development of mice from enucleated oocytes injected with cumulus cell nuclei Nature 394 369-374

Wang WH, Machaty Z, Abeydeera LR, Prather RS and Day BN (1998) Parthenogenetic activation of pig oocytes with calcium ionophore and the block to sperm penetration after activation Biology of Reproduction 58 1357-1366

Wilmut I, Schnieke AE, McWhir J, Kind AJ and Campbell KHS (1997) Viable offspring derived from fetal and adult mammalian cells Nature $385810-813$

Yang X, Presicce GA, Moraghan L, Jiang S and Foote RH (1994) Synergistic effect of ethanol and cycloheximide on activation of freshly matured bovine oocytes Theriogenology 41 395-403

Yoshida M, Ishizaki Y, Kawagishi H, Bamba K and Kojima Y (1992) Effects of pig follicular fluid on maturation of pig oocytes in vitro and on their subsequent fertilizing and developmental capacity in vitro. Journal of Reproduction and Fertility 95 481-488

Received 2 January 2001.

First decision 19 February 2001.

Accepted 27 March 2001. 